Revista Iberoamericana, Vol. LXIX, Núm. 205, Octubre-Diciembre 2003, 863-879

\title{
UN IMPASSE IDEOLÓGICO: CARNAVAL, VISIBILIDAD Y PROTESTA SOCIAL EN UNA NACIÓN POSCOLONIAL ${ }^{1}$
}

POR

\author{
Gerard Aching \\ New York University
}

\begin{abstract}
Tenemos que vivir como pueblo, pueblo. Tenemos que alzarnos. Alzarnos. Pero, ¿cómo se alza uno cuando sus hermanos hacen las paces por un puñado de dólares, cuando sus hermanas venden sus almas, y las madres y los padres a sus hijos? ¿Cómo puedes alzarte si hay una renta que pagar y unos niños que llevar a la escuela, y cuando ves al hambre desfilar por tu patio y acampar en tu casa?

Aldrick pronunció unas palabras de las cuales estaría muy orgulloso mucho después: "No lo sé".
\end{abstract}

Earl Lovelace, The Dragon Can't Dance ${ }^{2}$

En el momento culminante de su improvisado discurso ante una muchedumbre que les seguía a él y a sus "guerreros" en plena rebelión contra la pobreza, el protagonista de The Dragon Can’t Dance [El dragón ya no baila más] (1979) pronuncia unas palabras insólitas. En esta novela del trinitario Earl Lovelace, la rebelión llega a su fin con la captura y el proceso judicial de los rebeldes, lo que no les impide expresar su satisfacción por haber atemorizado a sus conciudadanos y haberlos obligado a reconocer sus demandas de justicia social. No obstante, aún queda por resolverse un asunto poco estudiado pero crucial que menciona Aldrick en su discurso. En este instante -clave para la propagación de su mensaje- en el que se dirige a un grupo de seguidores que escuchan su denuncia del empobrecimiento y la opresión, ¿por qué opta por proclamar un anticlimático "no lo sé”? Más aun, ¿de dónde proviene la sensación de orgullo que siente el protagonista cuando

\footnotetext{
${ }^{1}$ Lo explorado en este artículo es analizado con mayor detenimiento en el primer capítulo de mi libro Masking and Power: Carnival and Popular Culture in the Caribbean. Le agradezco a Miguel Ángel Balsa Marín su colaboración en la traducción de este artículo.

${ }^{2}$ A diferencia de otros escritores trinitarios de fama nacional e internacional, como V.S. Naipaul, Earl Lovelace declara frecuentemente su satisfacción por no haberse marchado de Trinidad y Tobago para hacerse novelista. Es uno de los escritores más reconocidos del país. Sus obras más famosas son The Dragon Can't Dance (1979), The Wine of Astonishment (1982) y Salt (1996), y se concentran por lo general en los sectores populares de la nación. La última fue premiada con The Commonwealth Writer’s Prize en 1997.
} 
hace una revelación que, al menos en apariencia, resulta tan inoportuna? Propongo contestar estas preguntas en este estudio, con el objetivo de abrir un diálogo que ponga fin a la ausencia de análisis en torno a la enigmática respuesta de Aldrick, carencia ésta que ha generado algunos malentendidos acerca de cómo se manifiesta y resuelve la protesta social dentro y fuera del carnaval trinitario. Me propongo mostrar aquí que el "no lo sé" del protagonista representa un impasse ideológico en el cual se vinculan y se desencuentran al mismo tiempo tres prácticas cuyos nombres tienen en su raíz el concepto de "posesión": desposeimiento, no-posesión y autoposesión. En términos globales, estas prácticas constituyen la inversa del grito utópico de “todos somos uno”, el cual se lanza durante las festividades pero que suena cada vez más falso a medida que se ponen de manifiesto distintas modalidades de enajenación en la comunidad de Aldrick.

Estas tres prácticas nunca aparecen ni aisladas ni estáticas en la novela, sino que se entretejen constantemente para trazar las transformaciones habidas en la sociedad urbana de Puerto España durante los años setenta. La máscara del dragón puede considerarse tanto un tropo visual como una indicación material de estas transformaciones. Como bien señala Angelita Reyes, el surgimiento de figuras como el dragón en el contexto del carnaval debe verse como una expresión de la plenitud misma de la historia (68). ${ }^{3}$ Para demostrar cómo funcionaban estas prácticas durante aquella época, es preciso proceder a describirlas por separado.

La primera escena que el lector encuentra en el prólogo a la novela describe un panorama infrahumano habitado por una población desposeída:

Éste es el monte, el monte del Calvario, donde el sol se pone sobre el hambre y sale sobre calles quebrantadas, tronos para perros callejeros cuyas costillas parecen cuerdas de banjo, calles en las que la basura se apila como una aguja de catedral centelleante de moscas que zumban como torpedos; y si quieres pasar de tu patio a la calle tienes que hacerlo como un atleta que saltara para superar la cloaca llena de agua sucia, conteniendo la respiración. Hay ruido todo el día. La risa no es risa; es un quejido que brota del pecho de estas casas -no, casas no, sino más bien chabolas que surgen del polvo rojo y de la piedra, tenues como el humo, frágiles como papel de cometa, tambaleándose sobre sus pilares que parecen palos de escoba posados sobre la nariz de un malabarista. (9)

\footnotetext{
${ }^{3}$ Las festividades oficiales del carnaval fueron inauguradas en la colonia española de Trinidad (1498-1797) por hacendados franceses. La primera oleada de éstos y sus esclavos salió de Granada, Guadalupe y Martinica para instalarse en la isla bajo la autoridad de la Corona española, interesada en acoger a hacendados católicos en la isla, poco poblada. La segunda oleada vino de Saint Domingue después de la Revolución Francesa (Anthony 1-2). Todos estos hacendados celebraban anualmente elaborados bailes de máscaras en los días previos al comienzo de la Cuaresma. Desde su comienzo, los carnavales se regulaban directa o indirectamente por códigos legales y religiosos. Desde 1838, año de la emancipación de los esclavos en la colonia inglesa, la mayor parte de las festividades abandonó los salones de los hacendados y los barracones de sus esclavos; a partir de entonces, las multitudinarias celebraciones pasaron a ocupar las calles de las ciudades. La mejor compilación de crónicas y proclamas sobre el carnaval después de la Emancipación es la de Michael Anthony. La mejor historia del carnaval de Trinidad hasta el momento es la de John Cowley.
} 
Más que un paisaje, se trata del retrato viviente de una pobreza ignorada que literalmente enmascara y se burla del "subdesarrollo" mediante su evocación de tronos, agujas de catedral y pilares. Este tipo de comunidades se ve orgullosamente representado por la máscara del dragón cuando, durante el carnaval, ésta se lanza a las calles de Puerto España y se inscribe fugazmente en el retrato de una nación en vías de modernización. Es precisamente en tal contexto donde mejor se entiende el término desposeimiento, al que recurro en este artículo para referirme al abandono político que han sufrido después de la independencia (1962) los distritos urbanos pobres como el antes mencionado.

Surge de este panorama un espíritu de rebeldía frente a la pobreza. Paradójicamente, no se manifiesta como un rechazo rotundo del desposeimiento sino como una ideología de la no-posesión a través de la cual los habitantes del Monte ("Hill”) trascienden su empobrecimiento material asiéndolo como si fuera su más preciada posesión. Es así como Aldrick y otros personajes cultivan con esmero su antimaterialismo. Según el narrador, por ejemplo, los mayores de la comunidad sobreviven en el Monte

\begin{abstract}
atesorando su pobreza como si de una posesión se tratara, atendiéndola con el mismo empeño que Miss Clothilda atiende las flores de su jardín, guardándola en su seno cual una llave maestra cuya función solo recordaban a medias, y que, ya oxidada, lucían como una joya, como un dije, como un medallón encantado cuyo poder mágico les otorgaba una misteriosa pureza, les convertía en la aristocracia de una resistencia que sus ancestros habían vivido durante toda la esclavitud en su incesante escapada -como cimarrones, esclavos fugitivos, negros del monte, rebeldes ... que afirmaban su humanidad en los más maravillosos actos de sabotaje que podían imaginar y practicar, creando una religión a partir de la holgazanería, la desidia, la estupidez y el desperdicio ... que se negaban a servir de grano para el molino de la maquinaria colonial. (10)
\end{abstract}

La no-posesión es, por lo tanto, una práctica histórica y una ideología al mismo tiempo. La idea de que el Monte engendra una orgullosa aristocracia de los pobres exige del lector un esfuerzo de imaginación que le ayude a entender cómo tal ideología podría valorar una forma de vivir opuesta a las iniciativas adoptadas por el país para fortalecer su economía tras su independencia. Dado que la no-posesión hunde sus raíces en una larga tradición de intransigencia, no se puede dar por sentado -como sugiere Diana Brydon-que el anhelo de trascender la pobreza sea unánime ni que esté limitado por un "hábito heredado de pensamiento dual” por parte de algunos de los habitantes del Monte (322). La complejidad de la novela va más allá de esta dualidad reduccionista y esencialista. Para Kenneth Ramchand, esta novela "erosiona el contraste entre los practicantes de la filosofía de la no-posesión y aquellos que discretamente se dedican a la acumulación de poder económico” (9). Richard D. E. Burton sitúa correctamente a los personajes a lo largo de un continuo entre la reputación y la respetabilidad (213-8). ${ }^{4}$

\footnotetext{
${ }^{4}$ La reputación y la respetabilidad son dos conceptos que el antropólogo británico Peter J. Wilson introduce en la literatura antropológica sobre el Caribe angloparlante para describir una dinámica importante en estas comunidades. A pesar de su dualismo sencillo en el texto de Wilson, siguen vigentes estos términos en su campo de estudio. Curiosamente, Wilson realizó sus investigaciones en una comunidad insular de angloparlantes negros en la isla colombiana de Providencia.
} 
En medio de los antagonismos entre la práctica oficial del desposeimiento y la ideología contracultural de la no-posesión, se encuentra la tercera práctica: la búsqueda personal de Aldrick en pos de su autoposesión, para fraguar una identidad propia después de que el Monte empiece a perder su integridad y, por consiguiente, se desvanezca paulatinamente el apoyo que sus habitantes prestaban al papel que desempeñaban el dragón y sus bailes ritualizados. Ya que la máscara y los bailes articulan estos antagonismos, el esfuerzo de Aldrick por encontrarse a sí mismo no puede separarse del sentimiento de pérdida que él y otros experimentan cuando eventualmente decide no presentar el dragón aquel año. La novela presenta una situación en la que la máscara tradicional ya no puede ni quiere inscribir su visibilidad en el espacio público durante el carnaval, al menos de la misma manera. De ahí que Aldrick, su antiguo creador y portador, busque otros modos de reafirmar su identidad social y personal, sobre todo a la luz de una ideología de la noposesión en pleno retroceso.

En este artículo, propongo una lectura detenida que contemple el rechazo de la máscara y los bailes, entendidos ambos como expresiones de una visibilidad camuflada de la protesta social en los espacios públicos durante el festival nacional. En consecuencia, planteo que cuando el protagonista se niega a construir y llevar su máscara, toma esta decisión impulsado por unas condiciones socioeconómicas que permanecen inalteradas desde la independencia. Otro aspecto relevante, y hasta ahora obviado por la crítica, tiene que ver con los límites de la acción que el protagonista impone sobre la rebelión abierta (libre de enmascaramientos) que lleva a cabo en las calles; tales limitaciones autoimpuestas reflejan un impasse ideológico que todavía hoy supone un desafío para los movimientos de protesta social en las Américas. El objetivo de mi estudio consiste en demostrar la existencia de profundas transformaciones en las formas simbólicas de la protesta social (la máscara, la parodia, la imitación) en Trinidad y Tobago, una vez conseguida la autonomía política.

Antes de proceder a un examen de las fundamentales contradicciones socioeconómicas que la novela retrata, es necesario que me detenga, siquiera brevemente, a comentar la conceptualización de la contradicción que se evoca en los bailes del dragón. ${ }^{5}$ Bettelheim, Nunley y Bridges plantean que, a pesar de sus orígenes diversos en el continente, los africanos en las Américas comprendían que el enmascaramiento era una combinación de "música, baile, disfraz, escultura y drama en una sola actuación” (35). Esta aseveración es cierta en cuanto al dragón y sus bailes, pero tiene consecuencias importantes para cualquier acercamiento crítico a la representación de contradicciones sociales por medio del baile. La emergencia de la contradicción en el baile puede distinguirse de la que se

\footnotetext{
${ }^{5}$ En un artículo escrito en 1956, Bruce Procope data el comienzo de la máscara del dragón en 1910. Procope ha escrito la descripción más detallada del origen de la máscara y el significado de sus bailes. Igual que la competitividad entre barrios o comunidades en los cabildos cubanos y las escuelas de samba en Brasil, cada barrio lucía su dragón, el cual, con el respaldo de su comunidad, se metía en "batallas" de bailes en los que el ganador era el dragón que improvisaba los movimienots más inimitables cuando se enfrentaba a otro dragón. Es importante observar que la victoria de un dragón se basa en su capacidad de imitar a otro dragón y en improvisar movimientos inimitables. Estas prácticas de contrapunteo se parecen a muchas otras de la diáspora africana. Para un análisis de las mismas, véase Thompson Drewal.
} 
encuentra en el discurso. Cuando Michel Foucault examina la contradicción discursiva, afirma que es "la ilusión de una totalidad que se oculta o queda oculta: tiene su lugar solamente en el hueco entre lo consciente y lo inconsciente, el pensamiento y el texto, la idealidad y el cuerpo contingente de la expresión. De todas formas, el análisis debe suprimir la contradicción lo mejor que pueda" (150, énfasis y traducción míos). En cambio, Vèvè Clark vincula el discurso y el baile cuando distingue entre los milieux de mémoire, o indagaciones sobre el baile, y los lieux de mémoire, es decir, los contextos de su escenificación. Para Clark, hay más proximidad entre la historia y la memoria en los lieux de mémoire de la diáspora africana que en el modo en que el análisis discursivo "presupone una distancia emocional e intelectual de la memoria y la historia en las investigaciones, por ejemplo, sobre la historia de la Revolución francesa” (188). En su novela, Lovelace se sirve de la técnica de evocar contradicciones socioeconómicas a través de la máscara del dragón y sus bailes para criticar la política del Estado-nación poscolonial. Esta técnica ilustra el argumento reciente del crítico Slavoj Zizek cuando arguye que “[l]a máscara no oculta únicamente el estado verdadero de las cosas; la distorsión ideológica está escrita en su esencia misma” (28).

\section{LA MÁSCARA DEL DRAGÓN: ENTRE EL DESPOSEIMIENTO Y LA NO-POSESIÓN}

En la lucha entre el abandono político de los barrios más empobrecidos y la ideología de la no-posesión que practicaban sus habitantes, el carnaval anual ofrecía la oportunidad de reclamar una visibilidad social a nivel nacional. Por lo tanto, el enmascaramiento en estos barrios no puede separarse de la resistencia contra la proclividad de los políticos a distraer la mirada. En este sentido, el carnaval es un asunto serio. El antropólogo Daniel Crowley observó que "los enmascarados se toman muy en serio a sí mismos y a las máscaras que llevan. Para ellos, no cabe duda alguna acerca de la importancia de sus actividades estéticas y el logro auténtico de ser reconocido como gran creador de máscaras por el público trinitario crítico” (179). Rex Nettleford plantea que las artes vinculadas a estas festividades son algo más que puras bufonadas, ya que tienen la virtud de afirmar el uso literal y metafórico de la máscara para sobrellevar un ambiente del que aún no pueden beneficiarse los sectores populares a pesar de la obtención de la independencia política (194). Para estos sectores, lo que empezó hace más de doscientos años como una subversión de las jerarquías sociales por parte de los hacendados y sus esclavos, se ha transformado en la oportunidad idónea para reafirmar la propia identidad frente a una historia de opresión socioeconómica.

La primera presentación de la máscara del dragón en la novela vincula la ideología de la no-posesión a la voluntad desinteresada de Aldrick de ponerse a disposición de la comunidad como su dragón. Aunque el público no atestigua la construcción de la máscara ni experimenta el ambiente de "santidad” o la "actitud reverente" con la cual el joven Basil le atiende a Aldrick, éste pretende que los espectadores interpreten los significados de su máscara y su actuación:

La verdad es que Aldrick se dirigía a su obra con espíritu sacerdotal; ya que, para él, la fabricación de cada disfraz de dragón era siempre un nuevo milagro, una nueva prueba 
no sólo de su habilidad, sino también de su fe: porque aunque sabía exactamente lo que tenía que hacer, sólo por medio de la fe podía avivar ese dragón sirviéndose de esos trozos de tela y hojalata, con la boca respirando fuego, su cola golpeando el suelo, el ruido metálico de sus nueve cadenas, todo contenía la belleza y la amenaza y el terror del mensaje que llevaba a Puerto España cada año. Mediante este mensaje afirmaba su ser ante el mundo. A través de él exigía que otros le vieran, reconocieran su persona, estuvieran sobre aviso acerca de su amenaza. (35-6)

Este deseo de reafirmar su identidad implica una previa invisibilidad social; este deseo emerge de la conciencia de que la ideología de la no-posesión surge en un distrito determinado de la ciudad (el Monte Calvario) y de que es solamente durante esta época del año cuando se permite la manifestación de la intransigencia de la comunidad a través del espectáculo y la explosión del espíritu carnavalesco. De ahí que Aldrick se valga de un disfraz espantoso y desconcertante para ostentar su invisibilidad social y la de su comunidad: "quería que todos lo vieran. Cuando lo vieran, debían estar ciegos para no ver" (124). En resumidas cuentas, el dragón no solo escenifica las contradicciones internas de la nación poscolonial -las que el observador de simpatías burguesas puede ver potencialmente y que rehúsa o deja de ver- sino que la máscara y sus movimientos ritualizados encarnan, como ha sugerido Zizek, la distorsión ideológica. El propósito de las actuaciones del dragón no es ocultar estas contradicciones sino reiterarlas.

Además de su papel como creador tradicional del dragón, Aldrick también se responsabiliza de evocar la identidad del Monte por medio del baile. A diferencia de los movimientos provocadores que obligan al público a tomar conciencia de la existencia social del Monte, este baile le sirve para construir una identidad afirmativa y espontánea. Cada año, pocos días antes del comienzo del carnaval, la comunidad se reunía espontáneamente en la vivienda de Aldrick. Como su coreografía había de ser un secreto, rehusaba presentarla públicamente. No obstante, a medida que acudía la gente y la curiosidad y admiración de los niños le alentaban, Aldrick desafiaba a uno de los niños a que imitase sus movimientos:

Y el niño daba un paso adelante, si era valiente, y si no, pues otro -un valiente- salía, y los hombres cantaban más alto y la música se calentaba, y el niño se colocaba enfrente, y bailaban, como si fuera un concurso, cada uno luciendo sus movimientos, cada uno luciendo su belleza, y al poco rato todos participaban, y el Solar cantaba y bailaba. No había un día fijo para que esto tuviera lugar, y aunque caía un día o dos antes del Carnaval, ocurría así: una emoción simplemente les invadía a todos y decían: "Vamos a donde Aldrick hoy”, y venían y la cosa ocurría sin más. Era como si el día se escogiera a sí mismo, y la gente viniera. (106-7)

Este pasaje destaca dos elementos importantes para nuestra comprensión de la función social de la máscara del dragón. En primer lugar, estos “concursos” de baile -como señala Bruce Procope en su estudio sobre esta máscara- tenían el propósito de alentar unas formas imitativas que pudieran trascenderse a través de la improvisación espontánea. En este sentido, este baile en nada se diferencia de los múltiples contrapunteos que caracterizan los rituales y artes de origen africano y de la diáspora africana en las Américas. Lo que hace Lovelace en su novela es más bien demostrar cómo este proceso 
de imitación e improvisación genera una identidad social. ${ }^{6}$ El segundo elemento tiene que ver con la construcción de una identidad social. Igual que cuando Benedict Anderson señala la importancia del acto simultáneo de leer periódicos y novelas para la concreción de una conciencia nacional, la actuación de Aldrick y el niño logra interpelar a su comunidad mediante una invocación espontánea del espíritu del carnaval y la inmediatez de un sentimiento de pertenencia. ${ }^{7}$

Aldrick asume su papel como tropo humano de significación histórica y genealógica cuando se pone la máscara, y esta acción le conduce a gozar de un lieu de mémoire muy particular. El primer día de carnaval brinda una serie de actividades y expectativas tradicionales: "con sólo un recuerdo que ardía en la sangre ... [Aldrick] tenía, cuando se ponía su máscara de dragón, la sensación de entrar en una máscara sagrada que le investía de una autoridad ancestral que le tocaba conservar ante la gente de este Monte, esta tribu naufragada tan lejos de la tierra que nunca había sido su hogar” (120). Según esta afirmación, este recuerdo que fluye por sus venas trasciende fronteras geográficas y desterritorializaciones impuestas y da origen a un sentimiento comunitario que se puede apreciar en el baile del dragón. Es decir, esta conciencia de un recuerdo que fluye en la sangre le permite a Aldrick definir, razonar y promover el Monte como parte íntegra de la diáspora africana. Y este es precisamente el vínculo que Aldrick establece cuando baila en las calles:

Durante dos días enteros Aldrick era un dragón en Puerto España, y se movía por las calles calurosas y ruidosas, bailando el baile del stickman, invocando a Sylvia e Inez y Basil y su abuelo y al Monte y a los compañeros de la Esquina, quienes se apoyaban contra la pared donde esperaban a que la policía los corriera. Era Manzanilla, el Monte Calvario, Congo, Dahomey, Ghana. Era África, el creador ancestral de la Máscara, afirmaba el poder del guerrero, se pavoneaba y se inclinaba, exhalaba fuego, arremetía contra sus cadenas, amenazaba con sus garras y decía a la ciudad: "Soy un dragón. Tengo fuego en la tripa y garras que me salen de las manos; ¡mírenme! Fíjense en mí, porque voy a quemar su ciudad. Voy a despedazarlos, miembro a miembro. (123-4)

En este papel de “creador ancestral de la Máscara”, Aldrick se identifica con la diáspora africana, es decir, con un sentido de pertenencia que imita y, por lo tanto, refuerza su identidad en un sentido afirmativo y edificante. ${ }^{8} \mathrm{Al}$ mismo tiempo, lo que no se puede

\footnotetext{
${ }^{6}$ Para muchos intelectuales, escritores y artistas caribeños, la importancia de la imitación o mimicry es una fuente de debates tan frecuentes como encendidos. Un ejemplo clásico de tal polémica es el que pretende establecer el Premio Nobel de Literatura de 1992 Derek Walcott con V.S. Naipaul, galardonado con el mismo premio en 2001. Walcott, citando dos novelas de Naipaul, The Loss of El Dorado y The Mimic Men, reprocha a este autor su incapacidad para imaginar las posibilidades creativas de la imitación. Frente a tal idea, Walcott destaca la imitación y la improvisación como actividades fundamentales para el artista o escritor caribeño. La postura de Lovelace recuerda a la de Walcott. Para una crítica perspicaz del espíritu romántico de las ideas de Walcott sobre la creatividad y la imaginación, véase Olaniyan.

${ }^{7}$ Véase Anderson.

${ }^{8}$ No cabe duda de que esta escena remite a una espiritualidad que también se puede encontrar en la práctica de ser montado -otra connotación de la voz inglesa spirit possession- por los orishas, por ejemplo, en los ritos de Regla de Ocha en Cuba, vaudou en Haití y Shango en Trinidad y Tobago.
} 
eludir, por razones históricas obvias, es el hecho de que su hogar caribeño fuera originalmente impuesto sobre él y sus antepasados. Este origen violento de la diáspora en las Américas nos ayuda a comprender que el afán nihilista del dragón por destruir la ciudad y amenazar a sus habitantes es una parte inherente de su coreografía, en la medida en que este impulso le permite comprometerse con formas evolucionadas de opresión socioeconómica. En cualquier caso, esta revelación de una identidad diaspórica representa la culminación de un proceso tradicional de enmascaramiento que empieza como el rechazo de una invisibilidad social impuesta. Por lo tanto, la máscara en este contexto no sirve para ocultar identidades, sino más bien para develarlas.

LA EMERGENCIA INVOLUNTARIA DE LA AUTOPOSESIÓN

En el carnaval de Trinidad y Tobago, tradicionalmente existía un acuerdo tácito entre los sujetos enmascarados (como el dragón) y el público, según el cual los primeros se abstenían de amenazar o abusar verbalmente de la concurrencia a cambio de una pequeña cantidad de dinero. Antonio Benítez-Rojo recuerda que había una costumbre similar en los bailes para matar culebras que se celebraban durante las festividades del Día de los Reyes en Cuba. ${ }^{9}$ En cualquier caso, Aldrick decide romper esa larga tradición al dejar de aceptar dinero: “Quería que le tomaran por una persona real, que no desaparecería sencillamente dándole una moneda” (124). La idea de que la amenaza del dragón no pueda esfumarse mediante un pago simbólico confunde y asusta a algunos asistentes, que reaccionan de inmediato tildándole de “enloquecido” e insistiendo en que está buscando problemas (124). Las acciones de Aldrick ponen al descubierto el estatus social de los asistentes, hecho que explica la vehemencia de las acusaciones que estos profieren como expresión de su ansiedad.

Este desenmascaramiento del público que acabamos de explicar produce una transformación profunda tanto en la máscara como en las actuaciones del dragón. La novela de Lovelace muestra cómo la solidaridad del Monte empieza a desintegrarse lenta e irrevocablemente. Como ya he señalado, el grito de "todos somos uno" es pronunciado por aquellos que han abandonado la ideología de la no-posesión del Monte y buscan alguna compensación por la ansiedad y culpabilidad que les genera su alejamiento de la comunidad. En primer lugar, si la solidaridad que sugiere ese grito fuera una realidad, ¿por qué proclamar lo que ya es evidente? En un período de creciente enajenación en la comunidad, resulta lógico que la desintegración del Monte se refleje en la decisión de Aldrick de no crear el dragón del año siguiente. Al tomar tal decisión, Aldrick empieza a reflexionar sobre su vida y futuro en vez de vivir con los ojos puestos en su actuación anual. Este ensimismamiento se intensifica a medida que “al dragón se le acaban hasta las fuerzas para hacer amenazas” (164), y a Aldrick le es cada vez más difícil seguir dedicándose por entero a su papel de dragón del Monte. Aldrick explica estas transformaciones como sigue:

Le parecía que perdían una batalla con los tiempos, con el pueblo del Monte. El pueblo quería seguir adelante, cambiar, hacer las paces con su condición, renunciar a la rebelión

\footnotetext{
${ }^{9}$ Véase Benítez-Rojo.
} 
en la que había vivido durante generaciones; mientras veían a Fisheye, Aldrick y los otros compañeros de la Esquina, cada vez más encajonados dentro de ese rectángulo de vereda y de calle junto a la tienda que hay al pie del Monte, como testigos de ese legado, que seguían luchando, cuyos ojos les molestaban, retaban y acusaban de abandonar su guerra santa, esa que ellos (Fisheye y Aldrick y los compañeros) seguían librando. Así pues esta gente comenzaba a mirarlos no tanto como a la conciencia perturbadora en la que se habían convertido, sino como a los principales causantes de sus problemas. (166)

En lo que respecta al Monte, Aldrick y Fisheye han sobrevivido a la necesidad de "guerreros" que tenía la comunidad. Lo obsoleto de las expresiones contraculturales es una evaluación tanto temporal como cualitativa; para Aldrick, perder la batalla con los tiempos parece coincidir con el final de una larga tradición de rebelión. Esta idea, según la cual el paso de una temporalidad "universal” y sus nociones subyacentes de progreso se consideran responsables de la erosión de formas contraculturales y sus prácticas subversivas, merece mayor detenimiento.

Para evitar una lectura romántica según la cual la novela sería primordialmente un lamento ante la obsolescencia de prácticas tradicionales, es preciso constatar que aunque The Dragon Can't Dance presenta en su elenco de personajes distintos grados de adscripción a la ideología de la no-posesión del Monte, la novela también es elocuente a la hora de exponer las razones por las que ocurren estos cambios profundos. Lovelace no retrata tales transformaciones como una pérdida aislada y homogénea, sino como un conjunto de sujetividades complejas que compiten entre sí e interactúan para dar lugar a la personalidad del Monte. En consecuencia, la política de baja intensidad en la que se basaba la eficacia social del dragón de Aldrick, se configura de forma diferente y "no tradicional”:10 "Algo había ocurrido. Ahora tenían empleos, eran responsables de la supervivencia de sus familias, ya no podían permitirse la rebelión de la Esquina... Sentían que debían elegir; porque sus mentes no podían manejar esas dos ideas contradictoriasla resistencia y la supervivencia, la rebelión y la decencia” (164).

Esta incapacidad para reconciliar tales contradicciones -en otras palabras, para situarse en una posición desde la que pudieran elegir, negociar y establecer los límites entre su reputación y su respetabilidad- explica por qué Aldrick se aparta de su papel inicial y de lo que éste implica. Sin embargo, cuando Aldrick renuncia a su máscara, ni puede ni quiere sustraerse de las condiciones socioeconómicas que le forzaron a él mismo y a su comunidad a adherir a la ideología de la no-posesión. Más bien, descubre involuntariamente que, en esta crisis de los "guerreros", la intransigencia que con tanto esmero ha cultivado y coreografiado bajo su máscara ya no necesita velos.

En esta nueva situación, Aldrick y Fisheye (guerrero impenitente y cimarrón cuya amenaza nunca se ve disfrazada en la novela) se complementan mutuamente en la

\footnotetext{
${ }^{10}$ En su importante estudio sobre el Atlántico negro, Paul Gilroy describe que la política de baja intensidad ["politics on a lower frequency”] surgió “bajo las narices de los capataces” (37) y que ésta se refiere a una "contracultura que reconstruye con aire retador su propia genealogía crítica, intelectual y moral en una esfera pública parcialmente escondida” (37-8). El filósofo Howard McGary también teoriza la existencia histórica de formas de resistencia de baja intensidad en su análisis de la resistencia inconsciente. Véase en particular el capítulo "Resistance and Slavery" del libro que escribió con Bill E. Lawson.
} 
coreografía improvisada de la protesta social. Dado que ambos habían sido los más destacados rebeldes del Monte, la política de baja intensidad de Aldrick y el ardor guerrero de Fisheye componían un continuo dinámico a través del cual el Monte Calvario podía reiterar su propia coherencia. Mientras Aldrick incuestionablemente promovía un sentimento de comunidad, Fisheye patrullaba las fronteras del Monte y demandaba valerosamente el pago de “peajes” a los “forasteros” como Pariag, el pequeño empresario indo-trinitario. La comunidad sentía respeto por ambos rebeldes, por su forma de combatir y derrotar a los dragones y a los "Bad Johns" ("guerreros" bravos y famosos) de otras comunidades, permitiendo así que el Monte mantenga y reconozca su propia fuerza e influencia colectivas. Al mismo tiempo, Aldrick y Fisheye cultivaban sus respectivas formas guerreras por separado; esto es, hasta que se vieron a sí mismos "cada vez más encajonados” en un pequeño espacio desde el cual tendrían que librar su "guerra santa”, aislados en un tiempo marcado por la conciliación. Resulta comprensible que ambos rebeldes, “portaestandartes de un ardor guerrero en trance de desaparición” (152), salgan de su confinamiento unidos por su empeño en continuar la lucha. Poco acostumbrado a esta flagrante exhibición y despliegue de fuerza desnuda, Aldrick abandona su política de baja intensidad y adopta las posturas y acciones agresivas de los Bad Johns.

La rebelión abierta es ese baile de dragón sin disfraces que Aldrick, Fisheye y sus compañeros ponen en escena. Tras cierta incertidumbre y un incidente imprevisto con un camión-“el milagro [que] ocurriría” (171) como prueba de lo relevante de la improvisación en la escena política- capturan a dos agentes de policía, se hacen con su jeep y se lo llevan por las calles de Puerto España. Disparan al aire, mientras se llaman a sí mismos Ejército de Liberación Popular e improvisan fieros discursos desde el vehículo, mientras rodean la Plaza de Woodford (el foro público al que Eric Williams, el primer primer ministro llamó la universidad de la Plaza de Woodford y desde la cual exigió la independencia del gobierno colonial británico en 1956). La “coreografía” improvisada es en sí misma un comentario sobre la naturaleza de la rebelión: "No necesitaban plan alguno. Pedir un plan era como cuestionar la verdad de la causa y el valor de sus soldados” (171). Aunque al principio duda, Aldrick descubre que su nuevo papel es similar al de la máscara de dragón durante el carnaval: "Sentía la calma que da la fuerza que tiene quien se sabe rodeado de milagros ... Mientras el jeep bajaba lentamente por la calle ... tenía la sensación de estar encarcelado dentro de un disfraz de dragón el martes de carnaval” (177). Este nuevo papel supone una cierta incomodidad -se siente "encarcelado"- pero su discurso improvisado indica que ese encarcelamiento viene marcado por un dilema del cual el confinamiento en el jeep resulta una metáfora apropiada:

No hagan las paces con la esclavitud... No hagan las paces, que ustedes han sobrevivido. Ustedes llenan los pueblos de chabolas, las prisiones, los arrabales, las esquinas de las calles, los manicomios, los burdeles, los hospitales. No hagan las paces con los barrios de chabolas, ni con la mierda de perro, ni con la orina. Tenemos que vivir como pueblo, pueblo. Tenemos que alzarnos. Alzarnos. Pero, ¿¿cómo se alza uno cuando sus hermanos hacen las paces por un puñado de dólares, cuando sus hermanas venden sus almas, y las madres y los padres a sus hijos? ¿Cómo puedes alzarte cuando hay una renta que pagar y unos niños que llevar a la escuela, y cuando ves al hambre desfilar por tu patio y acampar en tu casa? ¿Cómo puedes no hacer las paces? (179) 
Para Aldrick no parece haber planes más allá del levantamiento, más allá del jeep de policía del que se han apropiado y que termina por convertirse en la "prisión” de los rebeldes porque cuando necesitan alimento y gasolina no pueden arriesgarse a detenerse para conseguirlos. En cualquier caso, la rebelión abierta y el baile del dragón quedan equiparados a partir de este momento en la novela.

Cuando defiende su caso e indirectamente comenta el dilema y la impotencia que en apariencia se encuentran en el fondo de su rebelión, el abogado de los rebeldes traza ciertos límites en torno a su "baile”: "Las autoridades confiaban en que estos hombres fracasarían, por ello no intentaron detenerlos. Confiaban en que serían incapaces de emplear su frustración para otra cosa que no fuera el baile de un dragón, un gesto de amenaza; por eso no intentaron detenerlos” (183). Al confiar en que los rebeldes fracasarían, parece que las autoridades ponen toda su fe en la capacidad de sus propias máscaras de razón cínica para ayudarles a soportar las tribulaciones. ${ }^{11}$ Igualmente, mientras cumplen su condena en prisión, Fisheye valora su actuación en unos términos que recuerdan las amenazas de Aldrick de destruir la ciudad: “La verdá es que no m’han encerrao por cualquier cosa; hemos montao tremendo bochinche, ¿'eh? Tremendo bochinche. El susto que s'han llevao no ha sido pequeño, no. No sabían qué pensar, si íbamos a echar abajo el pueblo a tiros o qué. No hay dragón mejor” (186).

Aldrick se muestra de acuerdo y responde: "Sí, tremendo bochinche, tremendo dragón” (186). En tanto que es cierto que la máscara del dragón no puede bailar, es decir, que la propia máscara está perdiendo poco a poco su capacidad de convocatoria entre las comunidades que representaba, su coreografía todavía puede ponerse en pie. Fisheye defiende este punto de vista cuando asegura que los rebeldes han sabido atemorizar a la nación entera. Lovelace reafirma la importancia de esta dimensión de resistencia política sin disfraces y declara en una entrevista con $\mathrm{H}$. Nigel Thomas que "la misión de quien se ve restringido consiste en pelear contra las barreras que le impiden ser él mismo. Todo el asunto de la esclavización es una de esas barreras, y por eso es una preocupación primordial para alguna gente. Efectivamente, por eso al final de The Dragon Can't Dance puedes ver que Aldrick y Fisheye -la gente que no se ha rendido, es decir, que ha hecho de su resistencia una expresión viva de sí misma, de modo que su vida entera es luchar” (12).

LAS CONSECUENCIAS DEL RECHAZO DE LA MÁSCARA

Hay un consenso general entre la crítica en torno a la idea de que la incapacidad del dragón para bailar viene a expresar un lamento por la pérdida de la unidad, el espíritu de comunidad y el ánimo guerrero. De acuerdo con el marco de referencias que he empleado para examinar este lamento, lo que mejor explica esta serie de pérdidas es la relación entre la capitulación paulatina de la tradición y la ideología de la no-posesión, procesos ambos

\footnotetext{
${ }^{11}$ Para Zizek, la máscara de razón cínica es la que insisten en llevar los miembros de la cultura dominante como reacción al rechazo popular a la cultura oficial. Zizek afirma: "este cinismo no es una posición directamente inmoral, sino más bien una posición de moralidad que ponen al servicio de la inmoralidad” (29-30).
} 
que coinciden en el tiempo con la decisión de Aldrick de abandonar la máscara para ir en busca de una identidad propia y diferente de su papel como miembro de la comunidad.

Sin embargo, el análisis que hace Lovelace de la construcción y transformación del significado social y la resistencia dentro de la cultura nacional tiene implicaciones para el futuro que van más allá de la mera expresión de un lamento. Cuando establece vínculos directos entre el abandono de las prácticas simbólicas tradicionales (modos tradicionales de una política de baja intensidad) y la rebelión de los "guerreros” del Monte, Lovelace, en el fondo, está formulando una pregunta: ¿cómo podrán acceder a la esfera pública y a la visibilidad aquellas historias, vidas y gentes “invisibles” una vez que las prácticas que les ofrecían esa posibilidad ya no sirven para sustanciar sus quejas históricas? En opinión de Michael Dash, "tanto el carnaval tradicional como la revolución tradicional deben ceder el paso a una estrategia nueva que combine la impotencia con la resistencia, el consentimiento con las nuevas formas de oposición y autoconservación” (132). Lovelace indica que una alternativa factible a la enajenación es la rebelión abierta. Además, al igual que la espontaneidad e improvisación de la imitación definen en gran medida los bailes del dragón, el novelista asevera que tampoco se precisan planes ni movimientos organizados ni para ésta ni para otras formas venideras de levantamiento popular.

Hay dos contingencias que despejan el camino para este potencial alzamiento espontáneo. En primer lugar, la intransigencia del Monte no desaparece: las condiciones socioeconómicas que engendraron la ideología de la no-posesión no se esfuman sino que perduran con un mayor grado de sofisticación. Cuando Aldrick, en el momento más dramático del levantamiento, admite que no sabe cómo se podrá conservar el espíritu de rebelión y, al mismo tiempo, asegurar el bienestar económico de la unidad familiar, desvela el dilema al que se enfrenta el Monte. Pero esta atormentada duda, junto con la carencia de un plan, resulta más honorable que el camino que emprende el cantante de calypsos Philo, quien distorsiona el "todos somos uno" del Monte para convertirlo en su lema "Yo soy nosotros". ${ }^{12}$ La incipiente industria cultural del país es lo que permite a Philo adoptar semejante postura; tal industria le induce a confundir su competitividad en el mercado con su capacidad de representar a la comunidad a la que pertenecía previamente. Philo crea para sí mismo un modo de representación que se diferencia de la coreografía de inspiración colectiva del dragón, la cual, para perdurar, necesita del concurso de adversarios. En otras palabras, para Philo, la competencia no consiste en las prácticas recíprocas de una diferenciación interna (como en los bailes de Aldrick) sino en la exclusión de sus oponentes. Y esta disponibilidad de ese “yo” burgués fragmenta al Monte en diversos grados de adscripción a la ideología de la no-posesión.

\footnotetext{
${ }^{12}$ El calypso -una manifestación cultural aún más vieja que el carnaval en Trinidad- es un romance popular y mayormente urbano cuyas características principales son la brevedad, la improvisación y el ingenio. Por lo general, los calypsos comentan la vida diaria, eventos históricos, la política nacional e internacional, la cultura nacional, los deportes y la moralidad; pero también pueden ir más allá de sus parodias y sátiras y caer en insultos, burlas y obscenidades. Los mejores calypsos combinan artísticamente una melodía pegadiza y letras ingeniosas. Tradicionalmente, el cantante de calypso desempeñaba el papel de comentarista y vocero del pueblo y gozaba del respeto de los sectores populares del país, sobre todo durante la época colonial. Para más información, véase Cowley.
} 
La segunda contingencia tiene implicaciones políticas para el Estado-nación “autónomo”. Tras la independencia de Trinidad y Tobago se hace innecesaria la política de baja intensidad que se servía de la máscara para camuflar historias “no oficiales” y quejas históricas ante las narices de las autoridades coloniales. La independencia se interpreta como el repudio de las leyes y regulaciones coloniales que establecían qué se podía o no expresar en las calles durante los carnavales. No obstante, la persistencia de algunas contradicciones importantes vienen a desmentir la suposición generalizada de que la plena autonomía política sea un objetivo logrado. Tras la independencia, ¿qué ha venido a reemplazar, por ejemplo, la crítica que hacía el dragón de las condiciones socioeconómicas que le confinaban en el Monte y le condenaban a una invisibilidad social que él intentaba subvertir recurriendo a su ingenio, a su máscara y a su coreografía?

Después de cumplir su condena, Aldrick descubre la respuesta a esta pregunta cuando escucha asombrado que había dos mil personas llevando la máscara de dragón en Puerto España” (195). Sin embargo, desaparece su alegría cuando su informante le espeta: "No el dragón de verdad, tú sabes. El dragón lindo, el de lamé y seda y satén. El diablo lindo” (195). En un panorama más amplio, este giro hacia un carnaval "lindo", hacia unas celebraciones desprovistas de crítica (cuyo resultado ha sido la homogeneización contemporánea de las costumbres, de los ritmos musicales y de las letras de las canciones) y hacia la búsqueda de significados profundos a menudo a través de la nostalgia, es una queja repetida sin fin entre quienes observan los festivales caribeños en la actualidad. ${ }^{13}$

La posibilidad de reconocer y escrutar esta situación surge de una contradicción interna (y no de las presiones imperialistas procedentes del exterior) en virtud de la cual la celebración retórica de la independencia y soberanía de la nación ha sido utilizada para disfrazar la continuidad del orden socioeconómico colonial. Ambas contingencias, la persistencia de ese orden y el reconocimiento “oficial” de la autonomía política de la nación, se contradicen mutuamente sobre todo desde el punto de vista de quienes han experimentado escasas mejoras desde la independencia. Por lo tanto, cuando los rebeldes optan por dar vueltas alrededor de la Plaza de Woodford en un jeep de la policía, es como si esta maniobra (que puede interpretarse tanto como una crítica implícita a los políticos del país como un anhelo de justicia social) pudiera resucitar aquella esperanza que en su momento trajo consigo la independencia. Esta contradicción posindependentista no tiene otra vía de escape que no sea el levantamiento espontáneo y abierto que los rebeldes encarnan en la novela, especialmente desde el momento en que la retórica independentista implica que las máscaras contraculturales y su papel subliminal como conservadoras de las quejas históricas pierden su razón de ser en un Estado-nación autónomo.

\footnotetext{
${ }^{13}$ Justo antes de la independencia de la nación en 1962, se creó un Comité (Carnival Development Committee) para el desarrollo del carnaval. En 1991, el parlamento trinitario promulgó una ley (Law No. 9 of 1991) en virtud de la cual se establecía una Comisión (National Carnival Commission) para organizar y subvencionar el carnaval anual tanto en Trinidad y Tobago como en "ciudades satélites" donde ahora también se celebran estos carnavales de origen caribeño (New York, Miami, Toronto y Londres). Según esta última ley, la Comisión se encargará de "convertir el carnaval en una empresa nacional, cultural y comercial viable" (National Carnival). En cualquier caso, esta incorporación paulatina del carnaval a la nacionalización de la cultura ha aumentado tanto la estetización acrítica de los disfraces como la transformación de formas paródicas y satíricas en prácticas nostálgicas.
} 
La sensación que invade a Aldrick de que el jeep que él y los demás habían "reclutado" para su causa le recluía dentro de un disfraz arroja nueva luz sobre la naturaleza del levantamiento protagonizado por los rebeldes. Mientras está encarcelado, Aldrick interpreta esta sensación cuando recuerda que aun cuando tenían armas en las manos, aun con tanto poder, esperábamos que otra persona tomase alguna decisión... Aun cuando tenemos poder, cuando tenemos armas. Es como si no fuéramos nosotros. Quiero decir que somos nosotros pero que no somos nosotros, sino otra gente. Es como si nosotros actuásemos pero el actor fuera otro" (188). Aldrick se da cuenta de hasta qué punto el drama de apoderarse del jeep, secuestrar a los agentes de policía, disparar al aire y autodenominarse arbitrariamente Ejército de Liberación Popular era, a sus ojos, un guión escrito por otros, una forma de imitación desconocida que nunca hubieran deseado escribir, mucho menos escenificar. Sin embargo, esta alienación respecto a su propia "revolución” no significa que su baile de dragón resultara ser un fracaso. Brydon vincula el levantamiento de Aldrick con el alzamiento del Black Power en 1970 cuando destaca que

aunque la sincronización y naturaleza del “carnaval” de Fisheye y Aldrick lo separa claramente de la revolución de 1970, el alzamiento abortado de la novela sí comenta, al menos indirectamente, el fracaso de la rebelión auténtica. La mayoría de los informes se refiere a 1970 como un año de violencia típica de carnaval que, o bien continuó más allá de sus límites, o bien se transformó en una nueva energía revolucionaria nueva. (329) ${ }^{14}$

Con todo, el movimiento o revolución de Black Power de 1970 no puede reducirse a lo puramente carnavalesco, ya que esa nunca fue su intención; lo que fue realmente espontáneo fue la protesta. Raoul Pantin, periodista trinitario, informó entonces que el país “reverberaba con las pisadas de miles de pies, y con el rugido de miles de voces, ‘¡el poder para el pueblo!’. Fue una protesta callejera sin plan previo, realmente espontánea, que a primera vista parecía brotar de la nada. Pero tenía unos orígenes históricos más antiguos” (4). La idea de que la revuelta de la novela es “abortada” y de que el alzamiento real es un "fracaso" resulta plausible únicamente si el éxito de una revolución ha de medirse por el derrocamiento incontestable del gobierno. Aldrick deja claro que cualquier plan y, por extensión, la adopción de cualquier plan revolucionario, significaría “cuestionar

${ }^{14}$ El “Black Power Movement” de Trinidad y Tobago coincidió durante la década de los años sesenta con movimientos similares en el resto del Caribe, los Estados Unidos y el Reino Unido. Básicamente, buscaban promover la autoconciencia cultural y el liderazgo de la protesta social por parte de jóvenes negros. La irrupción espontánea del movimiento en las calles de Puerto España -que era, a su vez, una consecuencia parcial de las protestas surgidas en los años sesenta-vino a sumarse al descontento juvenil ante la evidencia de que los ocho años de independencia del país no habían traído consigo mejoras más sustanciosas para las condiciones de vida de la mayoría de la población. El uso del término "revolución" para describir este movimiento de 1970 se refiere a una revolución cultural, en virtud de la cual la intelectualidad del movimiento, junto con una gran parte de la juventud de color, empezaron a desprenderse del racismo que había sido internalizado por gran parte de los trinitarios durante la época colonial. A pesar de que sirvió para agravar una crisis política que, originada por varios factores, estaba teniendo lugar en este mismo momento histórico, el movimiento no llegó a derrocar al gobierno. 
la verdad misma de su causa”. En otras palabras, recurrir al miedo para que la población abra los ojos y vea las injusticias sociales -desenmascarar al público-son dos acciones que llevan el sello de un buen baile de dragón. Solo si el "éxito" se define en estos términos se puede conceder a Aldrick algún mérito cuando profiere ese sincero "no lo sé”. Sin duda, este personaje deplora la desintegración de la ideología de la no-posesión en el Monte, así como la alienación y el materialismo incipiente del barrio; pero, al mismo tiempo, Aldrick no le niega a la comunidad su libertad para trabajar y para educar y alimentar a sus hijos bajo el régimen instaurado tras la independencia.

El "no lo sé” de Aldrick marca los límites conscientes entre el desposeimiento y la autoposesión; el protagonista no está dispuesto a llevar su protesta callejera más allá de este umbral. Es ésta una decisión de la que se hace responsable a sí mismo y respecto de la cual se muestra orgulloso. Por lo tanto, mi lectura de la búsqueda que Aldrick emprende en pos de la autoposesión viene a subrayar la capacidad del protagonista para tomar una decisión consciente a pesar de encontrarse ante profundos dilemas nacionales, o, como Pantin lo expresa, “jóvenes negros de Trinidad ... se rebelan contra su propio gobierno negro, libremente elegido, en nombre del Black Power” (9). En otras palabras, la búsqueda de la autoposesión que realiza Aldrick no debe verse como el triunfo del individualismo sobre la alienación colectiva. Stephano Harney, por ejemplo, subraya que el abandono de la máscara del dragón por parte de Aldrick ilustra el modo en que Lovelace rechaza la identidad del grupo (44). Según Ramchand, "Aldrick puede empezar a participar en el sistema porque, gracias al surgimiento de un 'yo’ que se muestra ansioso por crecer, le es posible al fin poseer las cosas sin ser poseído por ellas, tomar parte en el mundo sin venderse a él” (10). En definitiva, la decisión de Aldrick de cuestionar su propia postura no es simplemente una manera de capitular ante unas circunstancias que le resultan abrumadoras; se trata más bien de un valeroso compromiso asumido por el protagonista, y ésta es la razón por la que más adelante se muestra orgulloso de su enigmática confesión. En último extremo, esta solución -la de poseerse a sí mismo prescindiendo del propio serno le devuelve al dragón su tradicional función significativa. Más bien, supone un intento de encontrar un espíritu de autoposesión que resulte adecuado para las inquietantes desigualdades que generan las contradicciones internas de la nación tras su independencia.

A todas luces, parece claro que aunque Aldrick afirma que no dispone de respuestas para las preguntas que él mismo plantea, no por ello admite su ignorancia ni su inocencia política. Efectivamente, lo que supone ese "no lo sé” es una respuesta tentativa ante una situación histórica sin precedentes. La decisión consciente de poner fin a la rebelión antes de que ésta traspase el punto sin retorno equivale, por parte de Aldrick, a un cauteloso voto de confianza a favor de la continuidad del régimen poscolonial. Para los defensores de éste, tal apuesta no solo se basa en las ventajas potencialmente liberadoras de las reformas democráticas, sino que también es, en último extremo, una llamada en favor de la equidad. Es desde esta óptica como mejor se comprende la disposición de Aldrick a defender la participación de su comunidad en el mercado.

Sin embargo, el relativo éxito económico de Trinidad y Tobago ha coincidido con un proceso de nacionalización y comercialización de las manifestaciones culturales locales que Lovelace ya anticipa en su novela. La subersiva máscara de dragón de Aldrick se ve multiplicada, estetizada, convertida en un conjunto de lindos disfraces más acordes con 
la creciente participación de la clase media en el festival nacional. Este aburguesamiento de las formas de expresión cultural locales viene a corroborar las observaciones de Néstor García Canclini, según el cual en América Latina lo “popular” ya no es monopolio de los sectores populares (155-6). Haciéndome eco de la inquietud manifestada por Lovelace, me gustaría finalizar este ensayo reiterando una pregunta que, en el umbral del nuevo siglo, sigue pendiente de respuesta: ¿bajo qué formas se concretará la resistencia frente a la “invisibilidad” social en una esfera pública cada vez más privatizada en nombre de la llamada cultura nacional?

\section{BIBLIOGRAFÍA}

Aching, Gerard. Masking and Power: Carnival and Popular Culture in the Caribbean. Minneapolis: University of Minnesota Press, 2002.

Anderson, Benedict. Imagined Communities: Reflections on the Origin and Spread of Nationalism. London: Verso, 1983.

Anthony, Michael. Parade of the Carnivals of Trinidad, 1839-1989. Port of Spain: Circle Press, 1989.

Benítez-Rojo, Antonio. “Caribbean Culture: A Carnivalesque Approach”. A History of Literature in the Caribbean. A. James Arnold, ed. Amsterdam: John Benjamins, 1997. 200-18.

Bettelheim, Judith, John Nunley y Barbara Bridges. "Caribbean Festival Arts: An Introduction”. Caribbean Festival Arts. John W. Nunley y Judith Bettelheim, eds. Seattle: University of Washington Press, 1988. 31-7.

Brydon, Diana. “Trusting the Contradictions: Competing Ideologies in Earl Lovelace's The Dragon Can't Dance”. English Studies in Canada 15/3 (Downsview, 1989): 319-35.

Burton, Richard D.E. Afro-Creole: Power, Opposition, and Play in the Caribbean. Ithaca: Cornell University Press, 1997.

Clark, Vèvè. "Performing the Memory of Difference in Afro-Caribbean Dance: Katherine Dunham's Choreography, 1937-87”. History and Memory in African American Culture. Geneviève Fabre y Robert O’Meally, eds. Cambridge: Oxford University Press, 1994. 188-204.

Cowley, John. Carnival, Canboulay and Calypso: Traditions in the Making. Cambridge: Cambridge University Press, 1996.

Crowley, Daniel J. "Midnight Robbers”. Caribbean Quarterly. [Issue dedicated to Trinidad Carnival] 3/4 (Mona, Jamaica, 1956). Rpt. in Trinidad Carnival. Port-ofSpain: Paria, 1988. 164-85.

Dash, J. Michael. The Other America: Caribbean Literature in a New World Context. Charlottesville: University Press of Virginia, 1998.

Foucault, Michel. The Archaeology of Knowledge and the Discourse on Language. A.M. Sheridan Smith, trad. New York: Pantheon, 1971.

García Canclini, Néstor. Hybrid Cultures: Strategies for Entering and Leaving Modernity. Christopher L. Chiappori y Silvia L. López, trads. Minneapolis: Minnesota University Press, 1995. 
Gilroy, Paul. The Black Atlantic: Modernity and Double Consciousness. Cambridge: Harvard University Press, 1993.

Harney, Stephano. Nationalism and Identity: Culture and the Imagination in a Caribbean Diaspora. London: Zed Books, 1996.

Lovelace, Earl. The Dragon Can’t Dance. Burnt Mill, U.K: Longman, 1979.

McGary, Howard y Bill E. Lawson. Between Slavery and Freedom: Philosophy and American Slavery. Bloomington: Indiana University Press, 1992.

National Carnival Commission of Trinidad and Tobago Act. Act No. 9 of 1991. 3rd Parliament, 5th sess., August 8, 1991.

Nettleford, Rex. "Implications for Caribbean Development”. Caribbean Festival Arts. John W. Nunley y Judith Bettelheim, eds. Seattle: University of Washington Press, 1988. 183-97.

Olaniyan, Tejumola.“Derek Walcott: Liminal Spaces/Substantive Histories”. Caribbean Romances: The Politics of Regional Representation. Belinda Edmondson, ed. Charlottesville: University Press of Virginia, 1999. 199-214.

Pantin, Raoul. Black Power Day: The 1970 February Revolution: A Reporter's Story. Santa Cruz, Trinidad y Tobago: Hatuey Productions, 1990.

Procope, Bruce. “The Dragon Band or Devil Band”. Caribbean Quarterly.[Issue dedicated to Trinidad Carnival] 4/3-4 (Mona, Jamaica, 1956). Rpt. in Trinidad Carnival Portof-Spain: Paria, 1988. 186-96.

Ramchand, Kenneth. "Why The Dragon Can’t Dance: An Examination of Indian-African Relations in Lovelace's The Dragon Can't Dance”. Journal of West Indian Literature 2/2 (Bridgetown, Barbados, 1988): 1-14.

Reyes, Angelita. “'All o’ We Is One’ or Carnival as a Ritual of Resistance: The Dragon Can't Dance”. African Literature in its Social and Political Dimensions. Eileen Julien, Mildred Mortimer y Curtis Schade, eds. Washington, D.C.: Three Continent Press, 1986. 59-68.

Thomas, H. Nigel. “From 'Freedom' to ‘Liberation': An Interview with Earl Lovelace”. World Literature Written in English 31, no. 1: 8-20.

Thompson Drewal, Margaret. Yoruba Ritual: Performers, Play, Agency. Bloomington: Indiana University Press, 1992.

Walcott, Derek. “The Caribbean: Culture or Mimicry”. Critical Perspectives on Derek Walcott. Robert D. Hamner, ed. Washington, D.C.: Three Continents Press, 1993. 51-7.

Wilson, Peter. Crab Antics: The Social Anthropology of English-Speaking Negro Societies of the Caribbean. New Haven: Yale University Press, 1973.

Zi•ek, Slavoj. “How Did Marx Invent the Symptom?” The Sublime Object of Ideology. London: Verso, 1989. 11-53. 